\title{
Societal References by Superhero Films in the 21st Century
}

\author{
Adrian Jimenez Ramos ${ }^{1}$ and Gabriel Brown ${ }^{1}$ \\ ${ }^{1}$ KIPP Colorado, Denver, CO, USA
}

\section{$\underline{\text { ABSTRACT }}$}

A wide variety of studies has identified a significant correlation between the income of a film and its genre. Unveiling that with newer genres and new audiences, certain movies experience more success than others. Here the researcher institutes a content analysis in which 12 live action 'superhero' films are viewed and evaluated based on a sophisticated code. The films are viewed multiple times and other 'outside' codes are also recorded by the researcher. The research results in a found correlation between economic success and the superhero genre is identified along with a greater understanding of the impact that the films have on audiences. Not only is the impact revealed, but also some methods are evaluated along with their effectiveness on the amount of income generated.

\section{Introduction}

The superhero comic genre began in the early to mid-1900s with the creation of characters with abilities that were deemed superhuman in a time conflicted by major events like World War 11, the Cold War, and the Civil Rights Movement (Smart, 2016). Several of the most popular superheroes, such as Superman, date back to these periods as the genre first experienced the success and connection of their characters to pertinent societal events (Karp, 2009). Superhero creators at the time intended to appeal their characters to the current events by engaging with people's concerns, fears, and struggles of the times (Smart, 2016). By appealing to the social factors at their given times, the characters gained popularity as they influenced the real-life people who undergo these events.

The superhero genre in the film industry has generated major movie titles responsible for changing the film industry itself in accordance with the films' prodigious financial gain. The relatively young cinematic genre has broken countless records, not only domestically, but worldwide with films like "Avengers: Infinity War" making history and becoming the fifth highest grossing film of all time with film return of 547.8 million dollars in the United States alone and 1.9 billion dollars worldwide (Bahr, 2018). Even though the success of superhero films, based on the recordsetting film profits, was evident, the factors that made the films successful were not.

Before the researcher attempted to identify what factors made superhero films so successful, it was important to understand what film success was and how it was to be measured. Films with the most success in the box office were associated with the term 'high grossing' due to their success domestically and worldwide as well (Follows, 2016). To be categorized as a successful film then, the film had to display economic success nationwide and worldwide based on the amount of income generated when the films released to audiences.

\section{Literature Review}

Various factors were anticipated to be responsible for the popularity of superhero films. One common factor that had shaped the success of most science fiction movies in general, was a studios' ability to apply technological advancements such as CGI, Computer-Generated Imagery, in order to properly fabricate fantasy realities or impossible scenes that were essential in science fiction plots (Abbot, 2006). A large part of making CGI possible in the film industry 
was being able to afford this technology. Therefore, the production budget of a film was a major factor in the amount of success the film was to have, for it determined what would be applied when producing the film (McAllister, M. 2006). The amount of money that a company had access to, influenced which big actors would appear on the film, the opening screens, and directors, among several other major economic decisions like CGI, which had been found to be in nearly all superhero films (Walls, 2005). For example, "Avengers: Age of Ultron, Avengers: Infinity War," and "Avengers: Endgame" all had a budget over $\$ 310$ million, putting them at the top 5 most expensive films ever made (Box Office Mojo, 2020). According to New York Times reporter Brooks Barnes, one of the listed films is the highest grossing film of all time, Avenger's Endgame, had a production budget of 350 million dollars, which may have contributed to the film generating 1.2 billion dollars worldwide(Barnes, 2019). CGI may come off as an essential part of a film in order to succeed; however, other genres also utilize CGI and do not succeed like the superhero films. For example, 2008's 'Speed Racer', a film largely based on computer generated racing scenes, had a 120 million dollar budget but only generated 94 million dollars worldwide (Box Office Mojo, 2020). Therefore, the success of movies in the superhero genre could not be solely attributed to CGI or production budget.

At the current moment, research had been done to qualify why superhero content was successful as presented in Talia Smart's, 'Superhero Popularity in Past and Present America', but no research had been done to find how, specifically, which of the many factors were responsible for the prosperity of superhero films. For example, in Talia Smart's research report, Smart sought to track the events that led to the success of superhero content in the early stages of the superhero genre (comics where superheroes first made their debut in pop culture). Smart was able to identify various factors including, the studios, budget, appeal to society, and special effects, among various other factors but did not narrow on any individually, Smart only identified them.

Unlike Smart, the researcher intended to select one of the influential factors in these films' success. Talia Smart, author of peer-reviewed academic journal, PIT Journal (The People, Ideas, and Things Journal), quoted the creator of Captain America, Jack Kirby, in the lines, "We weren't at war yet, but everyone knew it was coming, that's why Captain America was born; America needed a super-patriot. He symbolized the American Dream." The most popular heroes and plots were born out of the catastrophe in society. These characters and ideas of superheroes would have never been developed and much less given the popularity they have if the creators had not attempted to make references to society and its catastrophic events. Since various factors were undeniably responsible for the success of superhero films, the researcher chose to work with the results found by Talia Smart: superhero plots' references to society and their effects on box office performance. The results raised the question: To what extent do superhero films' plots make references to society and how influential are the references to the economic success of superhero films in the last two decades? Understanding what economic effects, positive or negative, these references have on films, would provide studios with a clearer and more direct guide on how to make successful films. Not only would this research study help studios economically, but researchers were able to further understand why and how humans are attracted to certain films. By narrowing the research to be based on superhero films specifically, and a specific factor, the researcher was able to measure the relationship that exists between humans and films in general which could have potentially led researchers to a new understanding about human culture. The researcher hypothesized that the ability of superhero films, and the genre in general, to change with society and adapt to societal occurrences and values, would have a positive influence on the prosperity of superhero motion pictures.

To determine the social situation at a given time period, the researcher looked to find the most impactful events of the 21st century. Professor of Popular Culture at Bowling Green State University, Jeffrey Brown, emphasized, "Through superheroes, America gets to be invulnerable, safe, and wins the day in the end. ... It's a way to deal with the fears that we all experienced with 9-11." An appeal to the human values of the current generation had proven to spark the success of superhero films, for these films had offered comfort for people since the occurrence of the most impactful event of the last 20 years: $9 / 11$.

Adding on to the effects of $9 / 11$, the work of Sociologist Louise Cainkar presented the major changes that had occurred since 9/11 as seen in her argument that, "Homeland security policies, in effect, have produced a great deal of homeland insecurity for special groups of people living in the United States." In addition, presented by Robyn 
M. Rodriguez of Sociological Forum, “The terrorist attacks elicited specific government responses after 9/11... The more aggressive enforcement of bureaucratic immigration policies, change of address policy... the enlisting of local and state police in workplace raids, and airport security sweeps..." The sociological source allowed for the researcher to understand the major shift in society due to the event that was $9 / 11$. The researcher was able to identify the fear of others as the major fear related to the events of 9/11. The fear was defined and identified in references through the illustration of immigration issues, terrorism, and strict safety precautions.

Subsequently, the Great Recession of 2008, Michael Overton and Robert L. Bland of the journal, State \& Local Government Review, presented, "The overall weakening of the economy in combination with the increasingly vitriolic bureaucrat bashing has undermined the public's faith in the fiscal solvency of public institutions." The Great Recession caused the nation to fear and not trust public institutions since it cost them their money and put them in positions they did not need during the Great Recession. The journal allowed the researcher to understand that a reference to the Great Recession would be depicted as the hesitation to be involved in any economics with the nation or being more cautious of how their money is saved and where it is placed since the Great Recession lost their money, and a risk like that cannot occur to the people again. Therefore, any scenes that reference individual economic success and distrust in the government would be identified as a reference to the distrust created by the Great Recession of 2008. The Great Recession of 2008 was often overlooked as impactful, but the largest plummeting of the United States economy does not occur every lifetime. Economic downfalls can be the most devastating to the nation as people are left struggling to survive, and money continues to inflate.

The last and most recent major event that the researcher chose to analyze as a major societal change was the Presidential Election of 2016. Authors in, The Journal of Economic Perspectives, Hunt Allcott and Matthew Gentzkow introduced the societal change in the lines, "Identifying fake news sites and articles also raises important questions about who becomes the arbiter of truth." The article, specifically these lines, allowed for the researcher to identify the last major fear which was the distrust in the government and specifically the media. The researcher was able to identify what references to this major event would be, based on the article because a reference to fears of the 2016 Presidential Election would be the mistrust of the government and the media. A reference would be depicted as the caution taken when accessing the media or issues regarding a falsification of information.

As shown in the prior research, the three most impactful events of the last 19 years had been the attack on 9/11, the Great Recession of 2008, and the Presidential Election of 2016. The major impact that each event had on the American society was evident through the major changes in concerns and policies at the time.

\section{Methodology}

In this study, the researcher performed a content analysis of both top performing American superhero films and low performing American superhero films. The researcher chose to look at both the high performing and low performing films to have a more accurate understanding of whether the plot decisions have any specific effects on the economic performance of a given superhero film. The films were selected through purposive sampling, two of the highest grossing films and two of the lowest grossing films, in order to determine societal situation based on each film's plot.

To begin research, the researcher needed to form a list of all the superhero films that had come out in the last 20 years. In order to limit confounding variables in the research and ensure that only references to society had an impact on the economic success of a film, the researcher chose to exclude the following: Rated R films, second releases, and films that were loosely based on superhero characters (not considered superhero films). Also, to have more narrowed results and a better understanding of the results, the research chose to only look at domestic performance and Marvel and DC films (the two largest providers with a total of 65 films combined). Lastly, the researcher chose to categorize the time groups four years after each major event to have the exact same number of years in each group, and so that the films remained relevant to the event closest to that time period.

After the researcher gathered the complete list of superhero films from the last 20 years (based on the guidelines made previously), the researcher divided the 20 years into the three-time groups mentioned: 2001-2005, 2008- 
2012, and 2016-2020. The three major events that the researcher divided the films by were the terrorist attack of $9 / 11$, the Great Recession of 2008, and the Presidential Election of 2016. Each of these events created specific fears. For example, 9/11 caused fear of the other since it was a terrorist attack, the Great Recession caused a fear of economic collapse, and the 2016 Election created a feeling of mistrust in the government. As seen in Kirk Baird's article, where Baird specifically looks at the terminology and events in films that relate to $9 / 11$, the researcher intended to look at all the aspects of film that could be relevant to the events (Baird, 2016). Following the researcher's division of the movies by the three events found, the researcher chose to look at the two highest grossing films and two lowest grossing films from each of the three time periods created.

After the films had been determined, the researcher looked into each event and found the major feeling most present at the time. The researcher took guidance from Talia Smart's content analysis where she looked into comic books to find that the plot and origin stories of the superheroes were entwined with the major events and feelings at the time. Therefore, the researcher applied a content analysis on films instead of comic books (Smart, 2016). These feelings were fears at the time. For example, during the election of 2016 a fear of government emerged; therefore, the researcher watched each film after 2016 to look for references to this fear. The researcher did this in order to have a narrow criterion as to what the researcher was coding and looking for. When each fear was identified and categorized, the researcher created a chart that properly identified each code/fear along with the event it was assigned to.

Figure 1: Key for Reference Codes

\begin{tabular}{|c|c|}
\hline Tally Type: & What it looks like in Film: \\
\hline 9/11 Reference & $\begin{array}{c}\text { Fear of Foreigner }(\mathbf{F o F}) \\
-\quad \text { Immigration discussion } \\
-\quad \text { Discrimination others } \\
-\quad \text { Attacks on/from different nations } \\
\text { Terrorism (T) } \\
-\quad \text { Skyscrapers collapsing (skyscraper destruction in general) } \\
-\quad \text { People in the street running and yelling } \\
-\quad \text { Planes crashing } \\
\text { Attacks on/from different nations }\end{array}$ \\
\hline $\begin{array}{c}\text { Great Recession } \\
\text { Reference }\end{array}$ & $\begin{array}{c}\text { Mistrust of Economy (MoE) } \\
-\quad \text { Hesitation to spend money } \\
-\quad \text { Personally holding money } \\
-\quad \text { Refusal to invest } \\
-\quad \text { Hesitation of banks } \\
\text { Stock Market Crash (SMC) } \\
-\quad \text { Hesitation of stocks } \\
-\quad \text { Avoiding economic involvement }\end{array}$ \\
\hline $\begin{array}{c}\text { Presidential } \\
\text { Election of } \\
2016 \text { Reference }\end{array}$ & $\begin{array}{c}\text { Mistrust of Government (MoG) } \\
-\quad \text { Surprise of new leader } \\
-\quad \text { No involvement with government } \\
\text { - } \quad \text { Not believing the government } \\
\text { Foreign Nation Interference (FNI) } \\
\text { False Information (FI) } \\
-\quad \text { Fake News } \\
\text { - Not believing the government }\end{array}$ \\
\hline
\end{tabular}




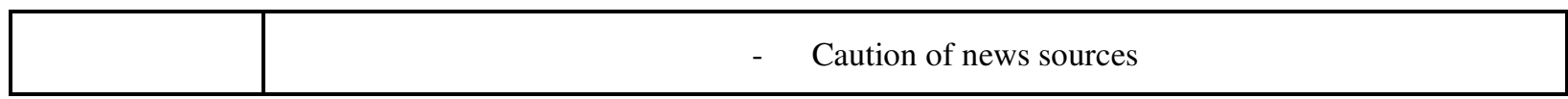

Each of the codes were tallied in a chart to find which had the most references to these fears. Another column collected the amount of references to the specific events at the time. When watching these films the researcher was pausing, rewinding, and reading captions in order to find as many references as possible and to ensure that the films are as coded and analyzed as possible. When a reference was found in a film, the reference was recorded with a timestamp and put into the chart along with a justification for the code it was labeled as and description of what the scene was doing. A total of three charts were made--one for each time group. Each graph consisted of the movie title, the domestic box office performance, the film's release year, the references made to the corresponding event, and the references to other unanticipated events. Each film was watched twice in order to ensure the researcher did not miss any references. The following graphs combined all the references found for each film.

\section{Findings}

Figure 2: Total References in All Films and Times

\section{Total References in All Films and Times}

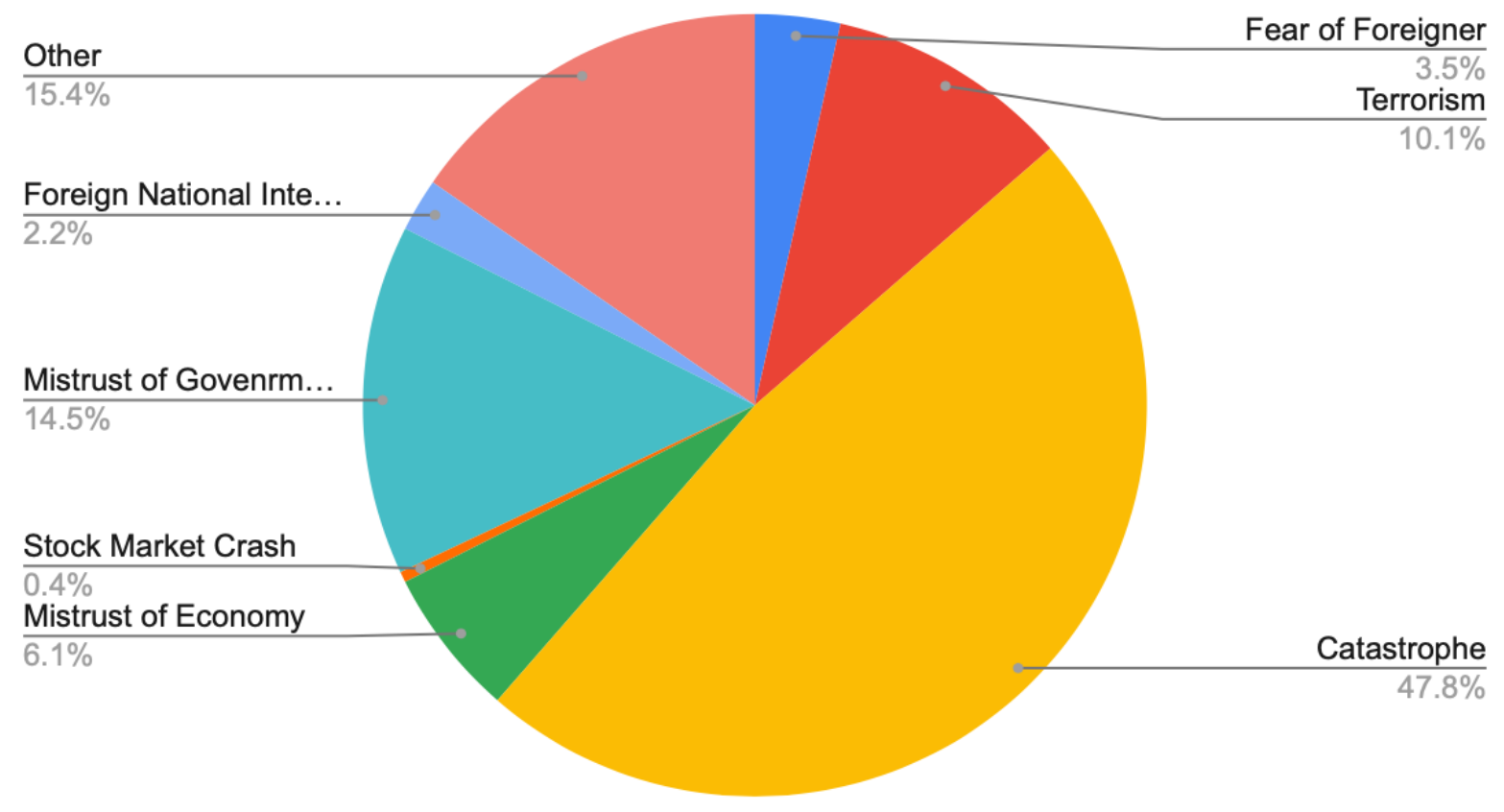

After collecting all the raw data, the researcher looked to present the data in pie charts to show the dominance of certain references over others. The first pie chart created presented all the references in all of the films combined, low grossing and high grossing. The researcher's charts were presented to depict the weight of each code on the films analyzed, high grossing and low grossing. Under each code label, the percentage of the total codes recorded was shown. The codes and their name were labeled to the right and left of the graph. The graph demonstrated the dominance of the references to "Catastrophe" in comparison to all the other codes combined since "Catastrophe" contained $47.8 \%$ of all the references, which was nearly half out of the 228 total recorded timestamps. The next code with the largest weight was "Other". This code referred to scenes in films that had a reference to society unidentifiable by the 
researcher, such as harassment in "Spider-Man," which was not associated with any major events. The "other" section took up $15.4 \%$ of the total time stamps recorded in all the films. In order to more closely analyze the references, new charts were created that divided up the total data by their time period and whether they were high or low grossing. The researcher also chose to remove the "Catastrophe" codes in the specified charts since they accounted for the majority of all of the time stamps and may be associated with the general core of the superhero genre.

Figure 3: 2001-2005 Low Grossing Films

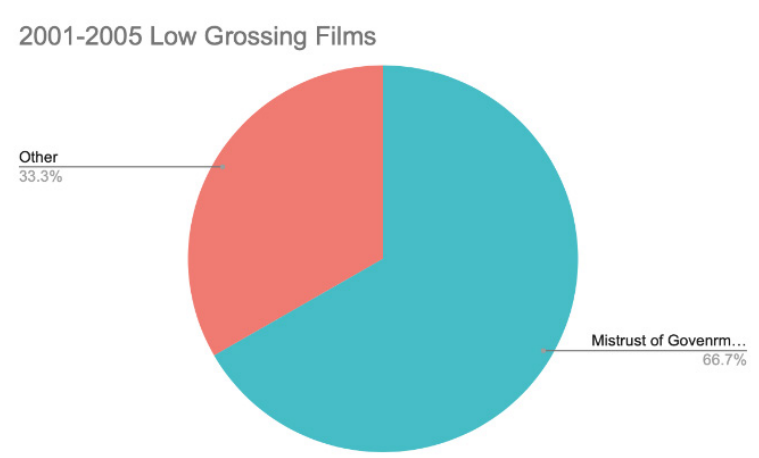

Figure 4: 2001-2005 High Grossing Films

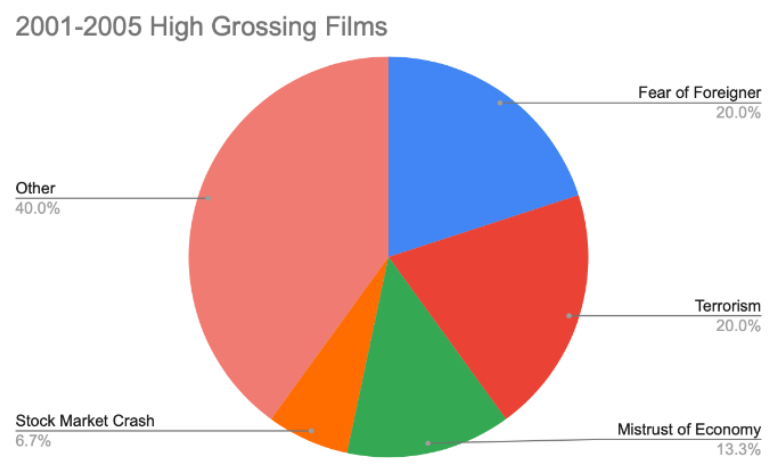

In the same time period, 2001 to 2005 , the low grossing films had no timestamps associated with the codes anticipated for the event of the time period which was $9 / 11$. In the high grossing films, on the other hand, $40 \%$ of their recorded timestamps were associated with 9/11 since they were under the codes "Fear of Foreigner" and "Terrorism." An unexpected $20 \%$ of the timestamps in the high grossing films fell under the codes: "Stock Market Crash" and "Mistrust of Economy," which are codes anticipated to only appear in 2008 to 2012 films due to the Great Recession of 2008. Both low and high grossing films of the early 2000s had an average of $36.65 \%$ of their timestamps undefined.

Figure 5: 2008-2012 Low Grossing Films

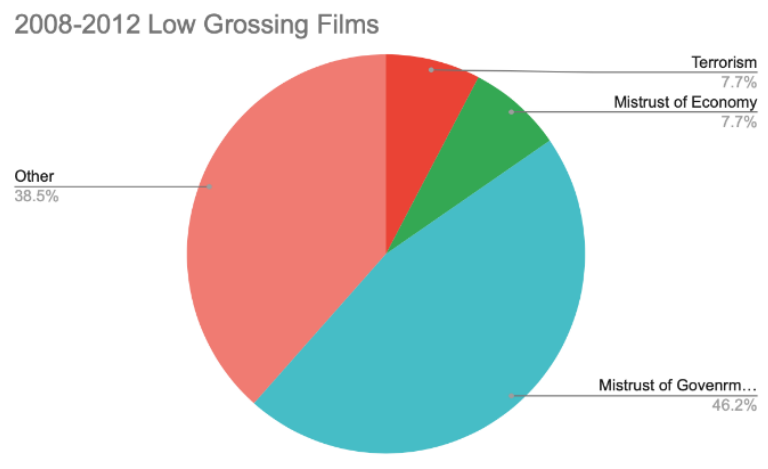

Figure 6: 2008-2012 High Grossing Films

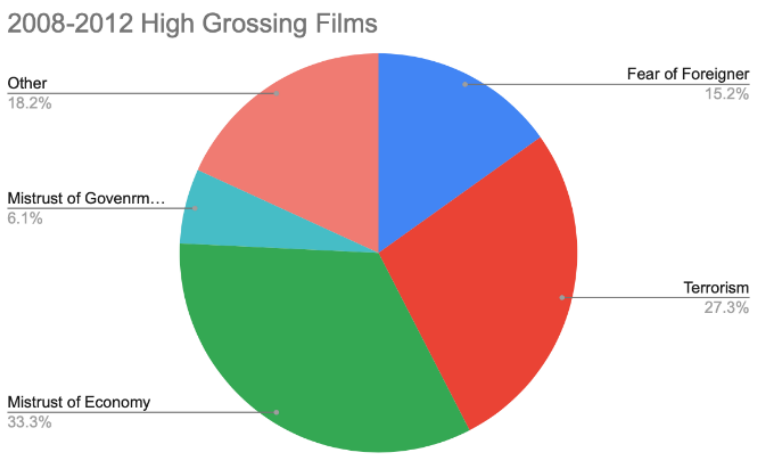

Films from 2008 to 2012 were the first films to have more identified references than undefined. High grossing films of the time had 33.3\% (largest weight) of their timestamps fall under the code "Mistrust of Economy" which was one of the anticipated codes to be tied with the Great Recession of 2008. With a similar weight, "Terrorism" projected for $27.3 \%$ of the total timestamps recorded. Codes that were anticipated to be tied with 9/11, "Fear of Foreigner" and "Terrorism" made up an average of $20 \%$ of the timestamps in the time period from 2001 to 2005 and saw a spike from 2008 to 2012 making up an average of $28.95 \%$ of the total timestamps in both the high and low grossing films analyzed. 
Figure 7: 2014-2019 Low Grossing Films

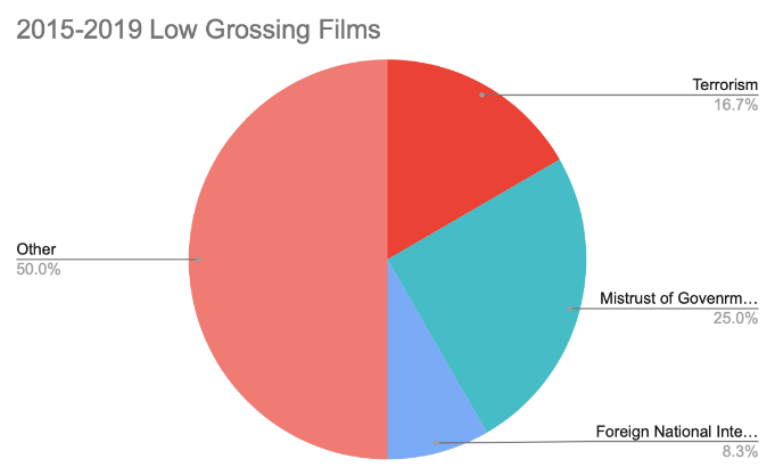

Figure 8: 2014-2019 High Grossing Films

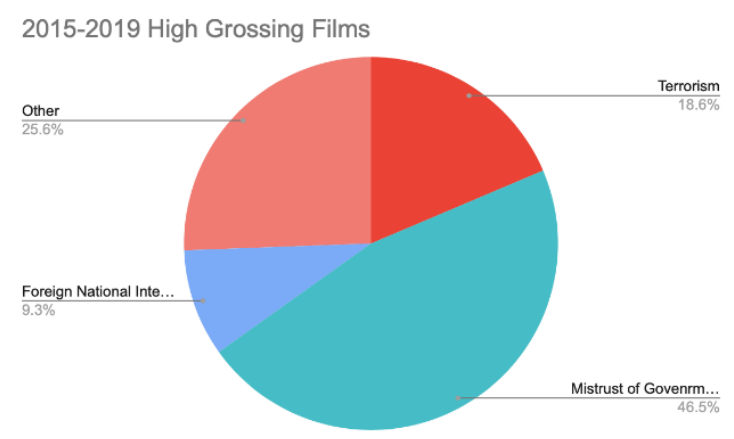

In the most recent time period, 2015 to 2019, associated with the Presidential Election of 2016, one of the major codes found in both low and high grossing films was "Mistrust of Government." The researcher successfully anticipated that the major reference found in the films of this time period would be "Mistrust of Government." In the same case as the 2008 to 2012 period, the code "Terrorism" made up an average of $17.65 \%$ of the timestamps in the 2015 to 2019 time period. Only three identified codes appear in the more recent films while in the films from the other two earlier time periods recorded up to four of the identified codes. The unidentified timestamps, recorded under "Other" took up an average of $37.8 \%$ of the total timestamps.

\section{Analysis}

The data seemed to support the researcher's hypothesis that more references made to society in a film would cause a film to have more economic success. Although the hypothesis seemed to be supported, a scatter plot and a residual plot needed to be conducted to properly identify whether any correlation existed between a film's grossing and the number of references made by that film since they were able to provide concrete evidence about the relationship between the two variables. The researcher chose to present a scatter plot and a residual plot with the inclusion of all films (identified by the color-coded table). The table presented the specific color that was associated with the film, as shown by the column to the right that stated the title of the film and the year of its release. Each major event was categorized specifically by a color: green, blue, and red. Each film within each major event was identified by a different shade of the color. 
Figure 9: Key for Reading Table

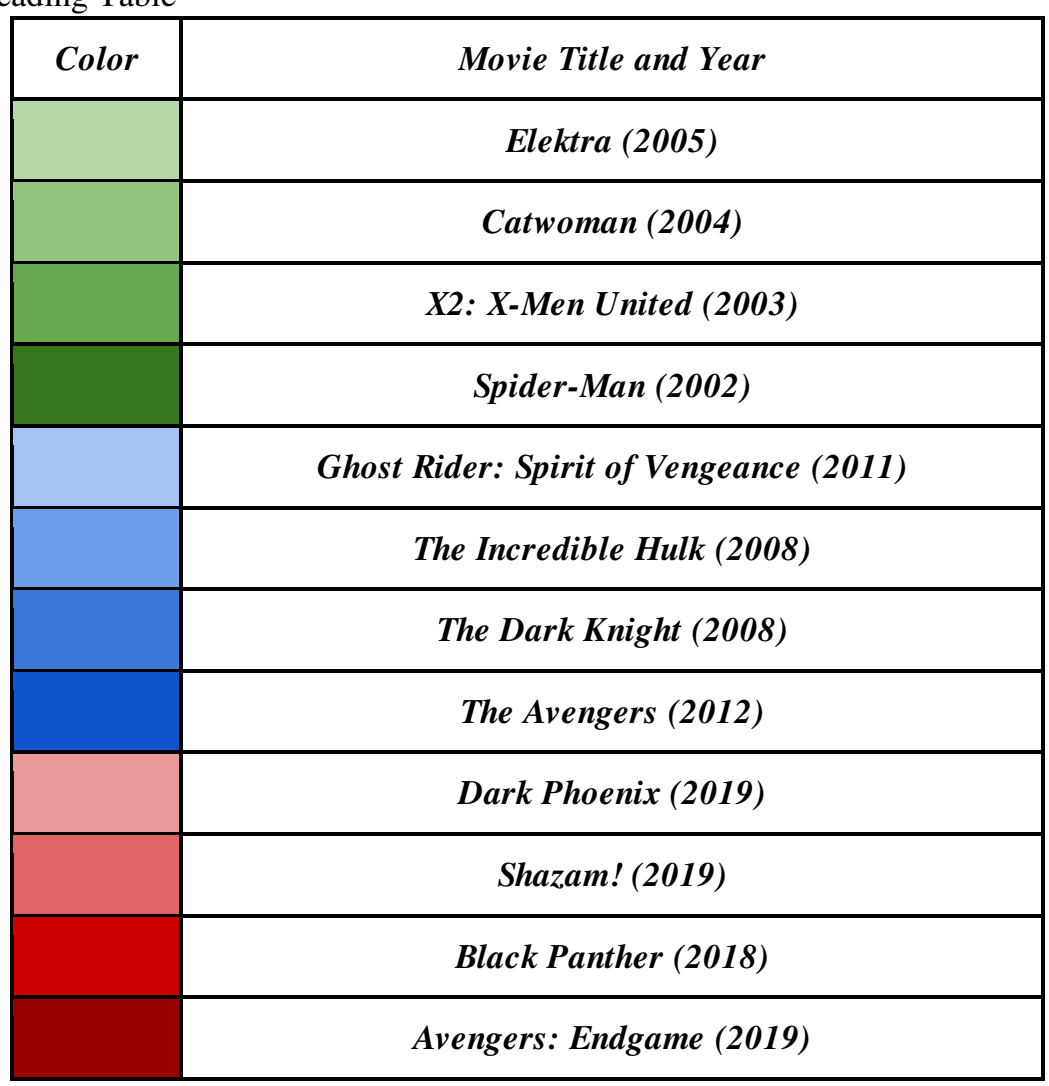

Figure 10: Grossing (\$) vs. Number of References to Related Major Event

\section{Grossing (\$) vs. Number of References to Related Major Event}

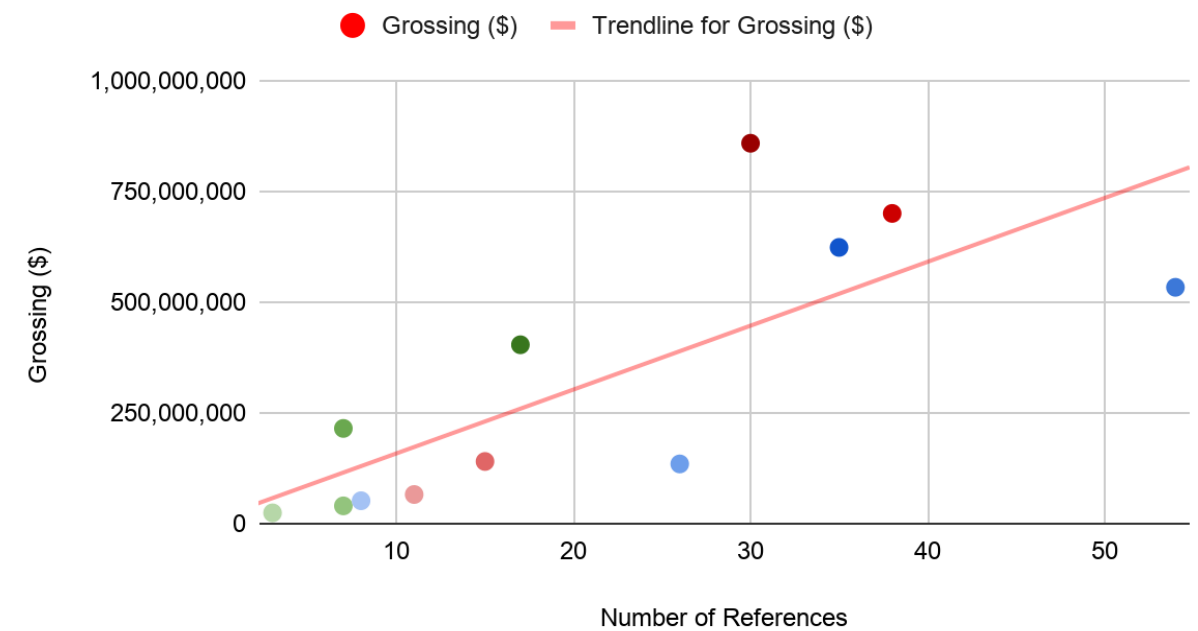

Without looking at specifics, just at a glance, the scatter plot appeared to show correlation. Although the correlation was not $100 \%$ true, some correlation did exist between the two variables which were a film's grossing and the amount of references it made to society. However, correlation could not be concluded from a visual assumption made from the scatterplot. 
Figure 11: Residual vs. Number of References to Related Major Event

\section{Residual vs. Number of References to Related Major Event}

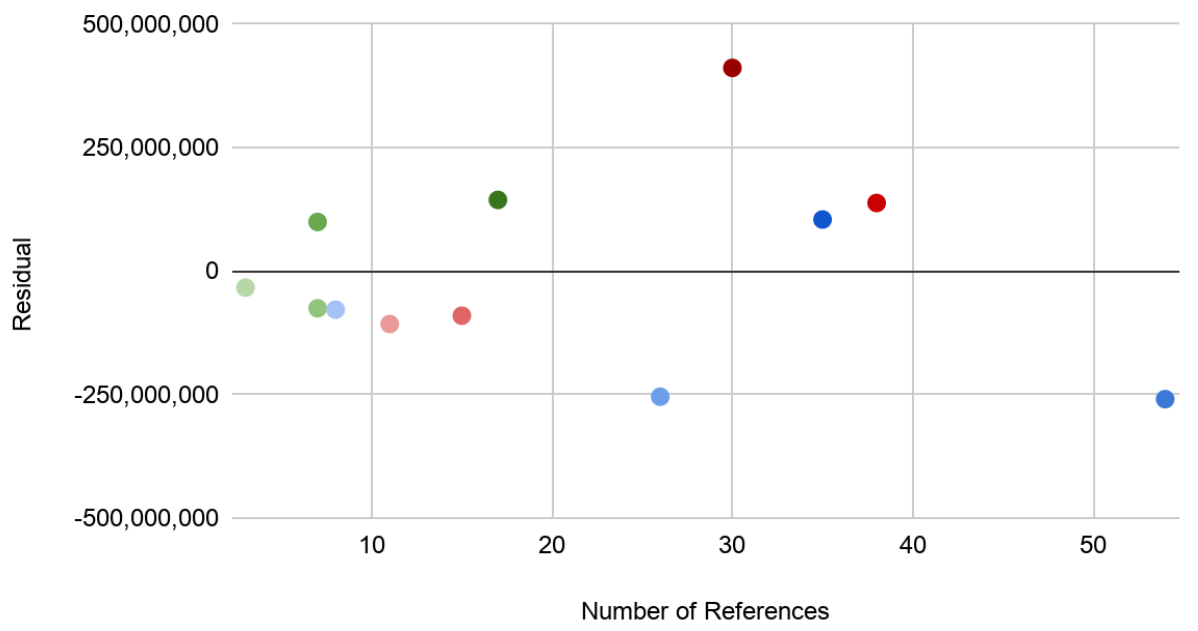

Therefore, the researcher decided to create a residual plot with the data retrieved from each of the movies which was also used to construct the scatter plot. A residual plot was used to plot the relationship between the variable on the xaxis, in this case the number of references made in the film to society, and the residuals on the vertical axis. If the data points appeared to be randomly arranged, then a line of regression model could appropriately prove correlation with the data's two variables, the number of references to society and the specific film. As seen in the residual plot, no pattern was visible, and the data points were randomly dispersed; therefore, statistically, it could be stated that correlation existed between the two variables. In order to more quantitatively describe correlation in the data, the researcher calculated the R-score from the residual plot. Values between 0.7 and 1.0 represented a strong positive linear relationship. The researcher calculated the R-Score of the data and found it to be 0.76 . An R-score of 0.76 showed a strong positive linear relationship between the number of references recorded in a film and the dollars in grossing made per film. Since a strong positive linear relationship was found, the researcher's hypothesis that there would be a positive relationship between grossing and the number of references in the film was supported.

Not only did the data clarify the correlation between grossing and references, but it also allowed the researcher to realize that the type of reference made was not necessarily aligned to the event. This was seen in the data as all the time groups demonstrated references to terrorism which was aligned to $9 / 11$. Perhaps this offered insight on the fact that 9/11 was by far the most impactful event of the last two decades, for the event made terrorism mainstream. Prior to $9 / 11$, terrorism was widely uncommon, but after the event, terrorism began to occur much more commonly and was more recognizable by the people.

\section{Limitations}

The researcher encountered various limitations along the research progress that may have interfered with the researcher's results. The first identified limitation in the research was that although the researcher watched the films twice, the researcher may have misidentified or missed certain references made to the major events chosen or other aspects of society. Missing or misidentifying references in the films may have caused the results to be changed since more "other" codes could have been marked or less references than actually found in the movies could have been counted towards the data. A future study could be done with more viewing rounds with possibly more people to have 
more solid results on the amount of references found in each film and what code the references fall in. Even though more views of the movies will make the results stronger, watching each film twice like the researcher did, still gave accurate results, for the researcher was able to watch the films at different speeds in order to not miss reference scenes.

Another limitation that the researcher found was that the sample size may have been too small to prove stronger correlation between the amount of references in a film to the amount of money generated by the film than actually found. A modified study could be constructed where the researcher chooses to randomly select a large sample size of at least $50 \%$ of the existing superhero films since the studios chosen have made less than 200 films combined. A larger sample size would take into account more superhero films produced by other studios, but the researcher specifically chose to only watch Marvel and DC studio films because they have been the most popular and largest providers of superhero films since superheroes were put in cinemas. The research looked specifically at these studios, the studios with the most popularity and the most success. By looking at these two studios, the researcher was able to work with films that had economic success. No other studio produces superhero films as successful as Marvel and DC films (Box Office Mojo, 2020).

Even with these limitations, the research done continues to show strong evidence supporting the existing correlation in the data for it is specific to a movie genre which was the superhero genre. Also despite the setbacks, the researcher made progressive advancements toward new information on superhero films. Not only was the correlation between references and economic success found, but various patterns were left to explore by the data. For example, when looking at the codes, 'catastrophe' was found in the majority of the films. This may prove to be a limitation, for the researcher had no way of anticipating this result and could not connect it to the research question. However, it could offer a strong step in a new direction specifically looking at the relationship between catastrophe and the superhero genre. Instead of looking at all the codes, a future study could look only at catastrophe and what effect it has on the audience, explaining the relationship between the two.

\section{Implications}

Although various factors impeded the researcher from acquiring more specific results, the correlation found was still a strong correlation that effectively proved the relationship that exists between the two variables, grossing and number of references made to society. The results presented studios with convincing evidence that suggested that films should include more references to society and would be more likely to prosper economically. This new understanding made it clear that studios must have considered the amount of references that they were making to society if they intended to generate the most income. Also, the findings presented an idea that the most successful studios may have already been recognizing the trend. As most of the high grossing films were from more recent years and almost all from Marvel Studios and Universal. Perhaps the way that these references are executed in film are the determining factors on the economic success of a film. On the other hand, the data also led the researcher to recall the factor that humans may appeal to superhero films because of catharsis. This helped build on to the idea that superhero films and the genre itself had grown so popular because there was comfort in movies that acknowledged all the events that humans went through, and by offering a superhero to fight these events in a fantasy universe, the films attracted a large amount of people responsible for the success of these films. This understanding not only supported the idea of catharsis with superhero films, but it provided evidence that allowed researchers and movie studios of other genres to make references to society. Not only were film studios pushed to acknowledge the events occurring in the real world, but also some studies in the sociological field were supported with these results that helped clarify certain parts of human behavior and society like entertainment. 


\section{Future Direction}

The researcher of this study chose to look at superhero films only, because the genre underwent a drastic increase in popularity in recent years. However, further research needs to be done to identify and differ whether the references made to society in a superhero film were intentionally looking to appeal to the audience, or if the references were a product of the genre itself for the genre's plots revolve around the idea of catastrophe. More specifically, a larger scaled execution (larger sample size, more film studios worked with, more people looking for references, etc.) of the same type of research and methods could make the findings more concrete. The research data collected and the understandings developed push future researchers to find if the correlation between a film and the number of references it made has an impact on all films' economic success, regardless of genre, or any other factor that was excluded from this research.

Along with unveiling whether the correlation only existed with superhero films, the research pushes future researchers to explore the feelings or thoughts triggered in humans by these references. Future studies can be done to understand why humans find comfort in movies about catastrophe. This study could look to present a film to the audience and survey them before and after the films. Also, future researchers can work with the effects of different events, meaning studies that compare the effects or presence of certain events in films or other social aspects of human society. The researcher responded to the uncertainty as to whether superhero films were affected by the amount of references that they included. This research was able to clarify and prove that the superhero genre succeeds when the storylines revolve around real life issues or events.

\section{Acknowledgments}

This project would not have been possible without the assistance of my mentors and companions who played pivotal roles in the development of my research paper. First and foremost, I am grateful for the guidance offered unconditionally by my research teacher Mr. Gabriel Brown. Moreover, I could not have accomplished these discoveries nor crafted my research in the way I did without the teachings of all my previous teachers, of all disciplines, who influenced my development as a thinker and more importantly, as a researcher. Last but definitely not least, I express my appreciation for my dear friends and family who believed, motivated, and encouraged me to persevere on this long journey.

\section{References}

Abbott, S. (2006). Final Frontiers: Computer-Generated Imagery and the Science Fiction Film. Science Fiction Studies,33(1), 89-108. Retrieved October 4, 2019 from http://www.jstor.org/stable/4241410

Allcott, H., \& Gentzkow, M. (2017). Social Media and Fake News in the 2016 Election. The Journal of Economic Perspectives,31(2), 211-235. Retrieved May 21, 2020 from www.jstor.org/stable/44235006

Bahr, L. (2018). Avengers: Infinity War Wins Box Office Again and Becomes Fifth Highest Grossing Film of All Time Worldwide. Time.Com, 1. Retrieved September 26, 2019 from http://search.ebscohost.com/login.aspx?direct=true\&db=a9h\&AN=129609844\&site=eh $\underline{\text { St-live }}$ 
Baird, K. (2016). Superheroes Are a Reflection On Society. Retrieved September 26, 2019 from https://www.toledoblade.com/KirkBaird/2016/03/25/Superheroes-are-a-reflection-on-so ciety/stories/20160324283

Barnes, B. (2019, April 28). 'Avengers: Endgame' Shows Movie Theaters Can Still Be on Top of the World. Retrieved May 20, 2020 from https://www.nytimes.com/2019/04/28/movies/avengers-endgame-box-office.html

Box Office Mojo. (2020). Retrieved May 21, 2020 from https://www.boxofficemojo.com/

Brown,J. A. (2019). The Modern Superhero in Film and Television: Popular Genre and American Culture. London: Routledge, Taylor et Francis Group.

Bahr, L. (2018). Avengers: Infinity War Wins Box Office Again and Becomes Fifth Highest Grossing Film of All Time Worldwide. Time.Com, 1. Retrieved September 26, 2019 from http://search.ebscohost.com/login.aspx?direct=true\&db=a9h\&AN=129609844\&site=ehSt-live

Cainkar, L. (2011). Homeland insecurity: The Arab American and Muslim American expereince after 9/11. New York, NY: Rusell Sage Foundation.

Follows, S. (2020, January 10). How movies make money: \$100m+ Hollywood blockbusters. Retrieved May 21, 2020 from https://stephenfollows.com/how-movies-make-money-hollywood-blockbuster/

Karp, L. N. (2009). Truth, justice, and the American way: What Superman teaches us about the American Dream and changing values within the United States (Unpublished master's thesis). Oregon State University. Retrieved May, 2020 from https://ir.library.oregonstate.edu/concern/graduate thesis or dissertations/3f462979m

McAllister, M. (2006). BlockBuster Art House: Meets Superhero Comic, or Meets Graphic Novel?: The Contradictory Relationship between Film and Comic Art. Journal of Popular Film \& Television, 34(3), 108-115. Retrieved September 29, 2019 from https://doi.org/10.3200/JPFT.34.3.108-115

Overton, M., \& Bland, R. (2014). The Great Recession's Impact on Credible Commitment: An Analysis of Private Investment in Tax Increment Financing Districts. State \& Local Government Review, 46(4), 282-297. Retrieved May 21, 2020 from www.jstor.org/stable/24639101

Rodriguez, R. (2008). (Dis)unity and Diversity in Post-9/11 America. Sociological Forum, 23(2), 379-389. Retrieved May 21, 2020, from www.jstor.org/stable/20110274

Smart, Talia. (2016). Superhero Popularity in Past and Present America. PIT Journal, 7. Retrieved September 23, 2019 from https://pitjournal.unc.edu/article/superhero-popularity-past-and-present-america 
Walls, W. (2005). Modeling Movie Success when 'Nobody Knows Anything': Conditional Stable-Distribution Analysis of Film Returns. Journal of Cultural Economics, 29(3), 177-190. Retrieved October 1, 2019 from http://www.jstor.org/stable/41810888 